\title{
Genetic assessment of a breeding population of black rhinoceros in Kenya using mitochondrial DNA D-loop sequencing
}

\author{
D.N. Thuo ${ }^{1,2,3}$, J.M. Kamau ${ }^{3,4}$, M.W. Kariuki ${ }^{3,6}$, F.M. Kibegwa ${ }^{1}$, \\ K.S. Kimiti ${ }^{7}$, J.O. Amimo ${ }^{1}$ and E.K. Githui ${ }^{3,5}$ \\ ${ }^{1}$ Department of Animal Production, University of Nairobi, Nairobi, \\ Kenya \\ ${ }^{2}$ Institute for Applied Ecology, University of Canberra, Australia \\ ${ }^{3}$ Institute of Primate Research, Nairobi, Kenya \\ ${ }^{4}$ Department of Biochemistry, University of Nairobi, Nairobi, Kenya \\ ${ }^{5}$ Molecular Genetics Laboratory, National Museums of Kenya, Nairobi, \\ Kenya \\ ${ }^{6}$ PAUSTI Jomo Kenyatta University of Agriculture and Technology, \\ Nairobi, Kenya \\ ${ }^{7}$ African Conservation Centre, Nairobi, Kenya \\ Corresponding author: D.N. Thuo \\ E-mail: david_thuo@yahoo.com
}

Genet. Mol. Res. 18 (2): gmr 18203

Received November 05, 2018

Accepted April 08, 2019

Published June 17, 2019

DOI http://dx.doi.org/10.4238/gmr18203

\begin{abstract}
The black rhino sanctuaries system has played a key role in repopulating and starting new subpopulations in Kenya. If this system is efficiently managed it may save the black rhinoceros from local extinction. Understanding the genetic status of endangered species is the most elemental sine qua non of animal breeding and conservation. It is therefore important to determine the genetic diversity of black rhino populations, especially of nucleus breeding populations that are used as a source of individuals for translocation and supplementation programs. We assessed the genetic diversity of one of the pioneer breeding subpopulations of the black rhino Diceros bicornis in Kenya using a mitochondrial DNA D-loop region. We then compared this subpopulation with the entire Kenyan
\end{abstract}


population to determine its status vis-à-vis the Kenya pooled population and determine the possible sources/relationships of the founder individuals. In the 469-bp D-loop region we analyzed, 7.11\% of the sites were variants, contributing to 18 distinct haplotypes. Estimates of genetic diversity using haplotype and nucleotide diversity metrics showed that the Lake Nakuru National Park subpopulation has a slightly lower genetic diversity when compared with that of the pooled Kenya population. The phylogenetic tree revealed that Lake Nakuru National Park founder individuals were probably sourced from multiple subpopulations. The dendrogram and the principal coordinate analysis plot indicated that the Maasai Mara subpopulation is not a distinct subpopulation, as had been suggested previously. Our results provide baseline genetic data for the Lake Nakuru National Park breeding subpopulation and valuable information for translocation/supplementation programs.

Key words: Kenya; Mitochondrial DNA; d-loop; Black rhinoceros; Translocations; Genetic diversity

\section{INTRODUCTION}

Maintaining high levels of genetic diversity has been identified as a key element for the long-term survival of populations (Willoughby et al., 2015). In various studies, high genetic diversity has been proven to be positively correlated with indicator values of animal fitness. For example, populations with a low level of genetic diversity have shown increased susceptibility to diseases and parasites (Frankham et al., 2002), increased juvenile mortality (Ralls, 1998), reduced adaptation and fitness (Frankham, 2005; Hedrick and Garcia-Dorado, 2016) and often exhibit an increased rate of extinction (Markert et al., 2010). Population genetics theory and data suggest that factors such as natural selection, genetic drift, lack of gene flow and small population size contribute to reductions in genetic diversity. Studies have further shown that animals facing a massive reduction in numbers and range are likely to experience an increased rate of extinction (Vandermeer and Goldberg, 2004). Such is the case with the black rhinoceros (Diceros bicornis).

The black rhinoceros is a species that has suffered one of the most dramatic declines of all mammals in recent history (Thuo et al., 2015). Currently, there are only 4,880 individuals remaining globally, a decline of more than $90 \%$ in a span of 40 years, and there are fears that this species will disappear from the wild within the next two decades (Emslie, 2012; Biggs et al., 2013). In Kenya alone, black rhinoceros numbers have catastrophically plummeted from an estimated 20,000 individuals in 1970 to about 631 in 2014 (Kenya Wildlife Service, 2012-2016). This decline has been mainly caused by loss and fragmentation of their natural habitats, as well as poaching, which is exacerbated by the tremendous growth in the retail price of rhino horn, from around $\$ 4,700$ per kilogram in 1993 to around $\$ 65,000$ per kilogram in 2012 (Amin et al., 2006; Biggs et al., 2013). As a result, the remaining small populations are now 
restricted to protected areas (Hilborn et al., 2006). In an effort to restore the black rhinoceros population in Kenya, a sanctuary approach was adopted whereby some subpopulations under high security comprise a nucleus breeding population to breed rhinos for subsequent translocations to their previously known historic habitats (Brett, 1990; Thuo, 2015; Githui et al., 2017) or to repopulate dwindling populations.

Whilst this approach has yielded success in rehabilitating black rhinoceros' populations, the risk of inbreeding and the possible impact of genetic drift in these closed subpopulations is unknown since no empirical genetic information was considered while selecting the founder individuals and no genetic supplementation has been considered yet for these subpopulations.

We investigated the current level of genetic diversity of a breeding subpopulation of black rhinoceros in Lake Nakuru National Park (LNNP), which was founded from animals threatened by poaching in various areas of the country and compared the levels of genetic diversity with other Kenyan subpopulations to establish how genetically viable the nucleus breeding population is. We also conducted a phylogenetic analysis to determine the relationship between and within subpopulations using a mitochondrial DNA control region (D-loop). The only major non-coding region of the mitochondrial DNA is the D-loop. This segment is the most variable part of the mtDNA and evolves five times faster than the rest of the mitochondrial genome. As a result, the mtDNA D-Loop has been used effectively in phylogenetic evaluations (Yacoub and Fathi, 2013), genetic diversity studies (Kawabe et al., 2014; Ashley, Melnick et al., 1990; Zhang et al., 2017) and population structure analysis (Rosetti and Remis, 2012). The results from this study will be helpful in the formulation of genetically driven translocation and supplementation programs.

\section{MATERIAL AND METHODS}

Lake Nakuru National Park (LNNP) is situated approximately $150 \mathrm{~km}$ northwest of Nairobi in Kenya's central Rift Valley on grid reference point $0^{0} 15 \mathrm{~S}$ and $36^{\circ} 7 \mathrm{E}$. The park covers an area of $140 \mathrm{~km}^{2}$ surrounding Lake Nakuru, which is the low point in a catchment basin of about $1800 \mathrm{~km}^{2}$. The park is home to about 60 black rhinos and as a priority area for their breeding it is fenced and well protected. The park is also a home to many other wildlife species, including some of the 'big five' such as the lion (Panthera leo), leopard (Panthera pardus) and the Cape buffalo (Syncerus caffer).

Samples of blood and tissue were collected from individuals in Lake Nakuru National Park (Table 1). Samples were opportunistically obtained during the routine Kenya Wildlife Service rhino management program, which includes ear notching, disease surveillance and translocation. Approximately 35\% of the total population was sampled and samples transported to the Molecular Genetics Laboratory of the National Museums of Kenya for further analysis. For comparative analysis mitochondrial DNA D-Loop data of Kenyan black rhinoceros were obtained from GenBank (Table 1). 


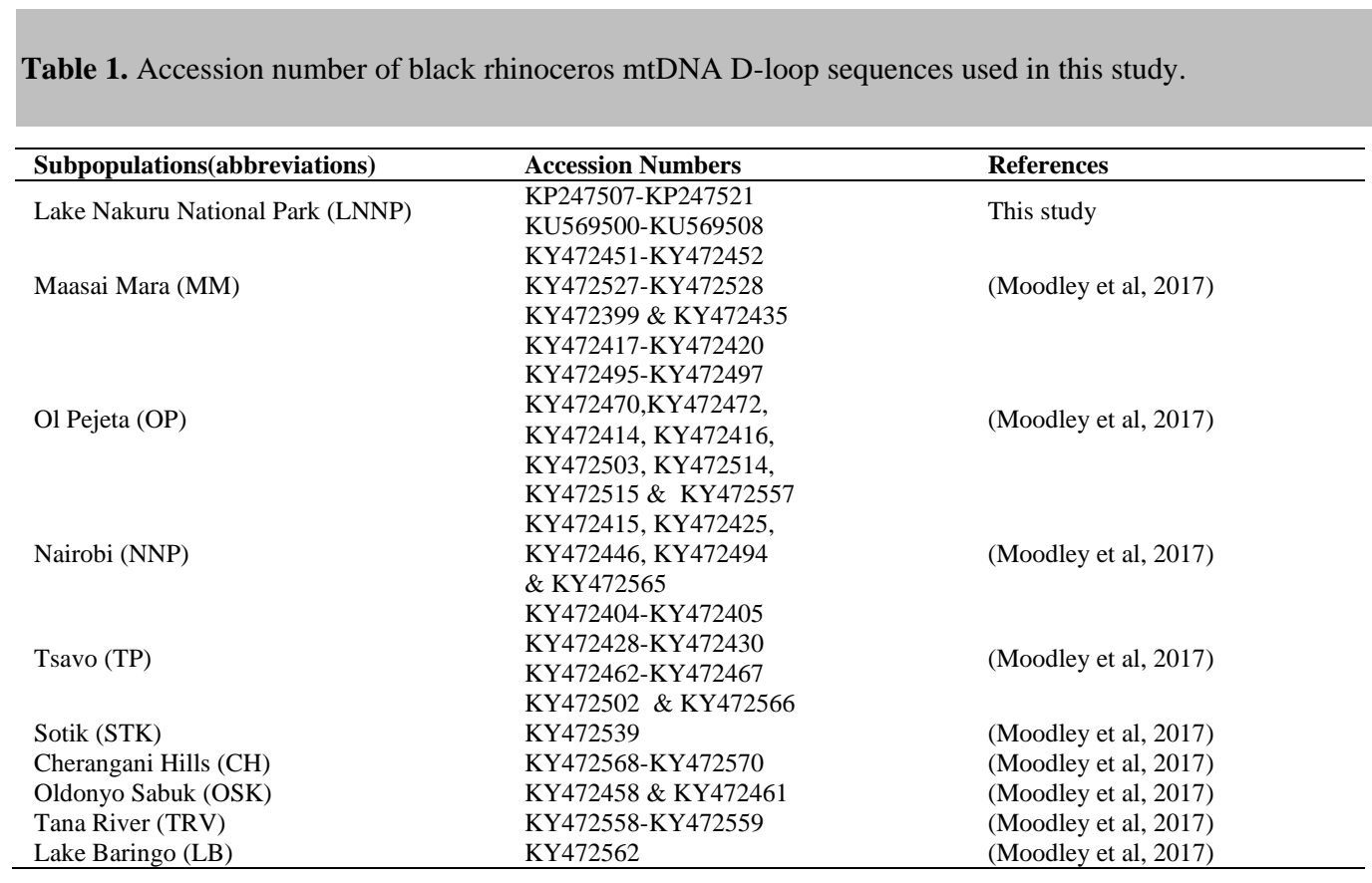

\section{DNA extraction, amplification and sequencing.}

Skin tissue sample and blood sample precipitates were centrifuged briefly, and ethanol aspirated. The samples were left to air-dry, and then washed in three volumes of $1 \mathrm{x}$ PBS to rehydrate. DNA was subsequently extracted using a Qiagen Kit, according to manufacturer's instructions (Qiagen Inc., Germantown, MD, USA) essentially involving lysis, binding of DNA to a silica matrix, and elution in $200 \mathrm{ul}$ TE $(10 \mathrm{mM}$ Tris HCL, $1 \mathrm{mM}$ EDTA, and $\mathrm{pH}$ 8.0). For tissues that were difficult to completely lyse, the phenol: chloroform method was applied (Green and Sambrook, 2012). The blood/tissue was incubated in $50 \mathrm{ug} / \mathrm{mL}$ proteinase $\mathrm{K}, 1 \%$ SDS in STE buffer $(150 \mathrm{mM}$ $\mathrm{NaCl}, 100 \mathrm{mM}$ EDTA, $10 \mathrm{mM}$ Tris $\mathrm{HCl}$, and $\mathrm{pH} \mathrm{7.4)}$ at $55^{\circ} \mathrm{C}$ for $3 \mathrm{~h}$. The lysate was subjected to phenol: chloroform phase separation and the upper aqueous phase containing DNA aspirated to a new tube. DNA was precipitated from the aqueous phase by adding 2-3 volumes of absolute ethanol. The pellet was suspended in 50 to $100 \mathrm{uL}$ TE (10 mM Tris HCL, $1 \mathrm{mM}$ EDTA, at $\mathrm{pH}$ 8.0). DNA concentration was measured by absorbance at $260 \mathrm{~nm} / 280 \mathrm{~nm}$ using a nanodrop spectrophotometer (Thermo Fisher Scientific) and the quality analyzed by electrophoresis in a $1 \%$ agarose gel in $1 \mathrm{x}$ TAE buffer (40 mM Tris acetate, $1 \mathrm{mM}$ EDTA, and $\mathrm{pH} 8.0$ ). The respective tubes with DNA were appropriately labelled and stored at $-20^{\circ} \mathrm{C}$.

Polymerase chain reaction was carried out using the following parameters: denaturation at $94^{\circ} \mathrm{C}, 1 \mathrm{~min}$ annealing at $54^{\circ} \mathrm{C}, 45 \mathrm{~s}$, and extension at $72^{\circ} \mathrm{C}$ for $1 \mathrm{~min}$. The primers flanking the $3^{\prime}$ end of cytochrome $\mathrm{b}$ and the D-loop middle region were used. The amplification product was verified on $1 \%$ agarose gels and the fragment 
excised from the gel solubilized in sodium iodide solution and then bound to a silica column in the gene clean procedure. Bound DNA was eluted in $30 \mathrm{uL}$ nuclease free $\mathrm{ddH}_{2} \mathrm{O}$.

Gene cleaned DNA of the amplified fragments was sequenced at Macrogen Inc., Europe (Netherlands), using Sanger's fluorescent dye chain terminator method. Each of the samples was independently sequenced three times and the raw sequences analyzed in Clustal-W program in BioEdit (Version 7.05). The edited raw sequences were submitted to the National Centre for Biotechnology Information (NCBI: https://www.ncbi.nlm.nih.gov) nucleotide database, GenBank accession numbers: KU569500-KU569508 and KP247507-KP247521

DNA extraction, amplification and sequencing procedures were similar to those in our previous study; for details see Githui et al. (2017).

\section{Data analysis}

The D-loop sequences were edited and aligned using ClustalW multiple alignment packages in BioEdit software (Hall, 1999). For comparative analysis, Kenyan black rhinoceros D loop sequences from GenBank (Moodley et al., 2017) were retrieved and included in the analysis. Sequences from this study and GenBank sequences were aligned as well. The haplotype diversity (Hd) and nucleotide diversity $(\pi)(\mathrm{Fu}, 1997)$ were calculated using DnaSP v5 software (Librado and Rozas, 2009). The statistical analysis was run for LNNP and KP separately and then pooled together to obtain the Kenyan black rhinoceros population estimates. Phylogenetic relationships among haplotypes were reconstructed using the maximum likelihood based on the Kimura 2-parameter model (Kimura, 1980). The genetic distance was calculated on the assumption of an equal substitution rate per site, and the robustness tested using 1000 bootstrap replications using MEGA version X Software (Kumar et al., 2018). Dissimilarity matrices and principal coordinate analysis were computed using DARwin 6.0 software (Perrier et al., 2003).

\section{RESULTS}

Table 2 shows the number of polymorphic sites, numbers of haplotypes, haplotype diversity $\left(\mathrm{H}_{\mathrm{d}}\right)$ and nucleotide diversity $(\pi)$ for LNNP, the pooled Kenya population (PK) and combined LNNP and PK. A total of 18 haplotypes from 34 polymorphic sites were found in 77 black rhinos based on the mitochondrial D-Loop region. When LNNP and PK were analyzed separately, the LNNP had nine haplotypes based on 17 polymorphic sites; this was slightly lower than the pooled Kenya populations' 13 haplotypes based on 28 polymorphic sites. LNNP had a lower haplotype diversity (0.767) compared to KP and LNNP + KP combined (0.898 and $0.870)$ respectively. Similarly, LNNP had a lower nucleotide diversity when compared to KP but slightly higher than LNNP + KP. The KP overall showed slightly higher numbers of polymorphic sites, haplotypes and greater haplotype diversity. The number of haplotypes calculated from all individuals together was less than the sum of number 
of haplotypes calculated from LNNP and KP separately due to some shared haplotypes among the populations.

Table 2. Number of polymorphic sites, number of haplotypes, haplotype and nucleotide diversity of LNNP and the pooled Kenya black rhinoceros populations. $\mathrm{n}=$ number of individuals in each population; $\mathrm{SD}=$ standard deviation.

\begin{tabular}{llllll}
\hline Population & n & $\begin{array}{l}\text { No of Polymorphic } \\
\text { sites }\end{array}$ & $\begin{array}{l}\text { No of } \\
\text { haplotypes }\end{array}$ & $\begin{array}{l}\text { Haplotype diversity } \\
\text { (SD) }\end{array}$ & $\begin{array}{l}\text { Nucleotide } \\
\text { diversity (SD) }\end{array}$ \\
\hline LNNP & 21 & 17 & 9 & $0.767(0.0081)$ & $0.099(0.0017)$ \\
Pooled Kenya (KP) & 56 & 28 & 13 & $0.898(0.0004)$ & $0.128(0.0128)$ \\
All (LNNP+PK) & 77 & 34 & 18 & $0.879(0.0007)$ & $0.013(0.0014)$ \\
\hline
\end{tabular}

Table 3 shows the distribution of haplotypes within the subpopulations. Five haplotypes: Hap_1, Hap_3, Hap_4, Hap_5 and Hap_8 appeared only in LNNP. Hap_15, Hap_12 and Hap_13 were the only other haplotypes uniquely harbored in single subpopulations: Ol Pajeta, Nairobi and Maasai Mara. All the other haplotypes were shared by individuals from different subpopulations; Hap_2 was the most widely distributed haplotype as it appeared in 23 individuals from five different subpopulations: LNNP, Maasai Mara, Tsavo, Oldonyo Sabuk and Nairobi.

Table 3. Distribution of haplotypes within the rhino subpopulations. NInd $=$ number of individuals assigned to each haplotype.

\begin{tabular}{lcl}
\hline Haplotype name & Nind & Individual sharing haplotypes \\
\hline Hap_1 & 2 & LNNP_R1, LNNP_R2 \\
LNNP_R3, LNNP-R2, LNNP_118, Chebii, Emma, Helga, Laban, Laban2, Peril, \\
Hap_2 & 23 & $\begin{array}{l}\text { Ryeta, KY472446, KY472451, KY472452, KY472453, KY472455, KY472458, } \\
\text { KY472461, KY472462, KY472463, KY472464,KY472465, KY472466,KY472467 }\end{array}$ \\
Hap_3 & 1 & LNNP_R12 \\
Hap_4 & 1 & LNNP_R47 \\
Hap_5 & 1 & LNNP_Latie \\
Hap_6 & 5 & LNNP_R116, Kiserian, LNNP_R8, KY472514, KY472515 \\
Hap_7 & 8 & Beth, KY472417, KY472418, KY472420, KY472421, KY472428, KY472429, \\
Hap_8 & KY472430 \\
Hap_9 & 1 & Leakey \\
Hap_10 & 6 & Zalia, KY472470,KY472472, KY472477, KY472478, KY472481 \\
Hap_11 & KY472399, KY472404, KY472405 \\
Hap_12 & 3 & KY472414, KY472415, KY472416, KY472419, KY472425 \\
Hap_13 & 5 & KY472435 \\
Hap_14 & 1 & KY472593 \\
Hap_15 & 1 & KY472494, KY472495, KY472496, KY472497, KY472502 \\
Hap_16 & 5 & KY472503 \\
Hap_17 & 1 & KY472526, KY472527, KY472528, KY472539 \\
Hap_18 & 4 & KY472557, KY472558, KY472559, KY472562, KY472565, KY472566 \\
\hline
\end{tabular}

Figure 1 shows the maximum-likelihood tree of 18 haplotypes from the whole Kenya population and one haplotype representing the out-group sequence. From all subpopulations, the dendrogram gave six clusters; all clusters harbored different individuals from different populations. Subsequently, no unique haplotype was observed as subpopulation shared haplotypes. Haplotypes in our target subpopulation (LNNP) clustered 
with the other haplotypes, LNNP individuals clustered in four of the six clades of haplotypes that were identified. In the dendrogram, only two clusters containing haplotypes Hap 12, Hap 16 and Hap 10 were not represented in LNNP.

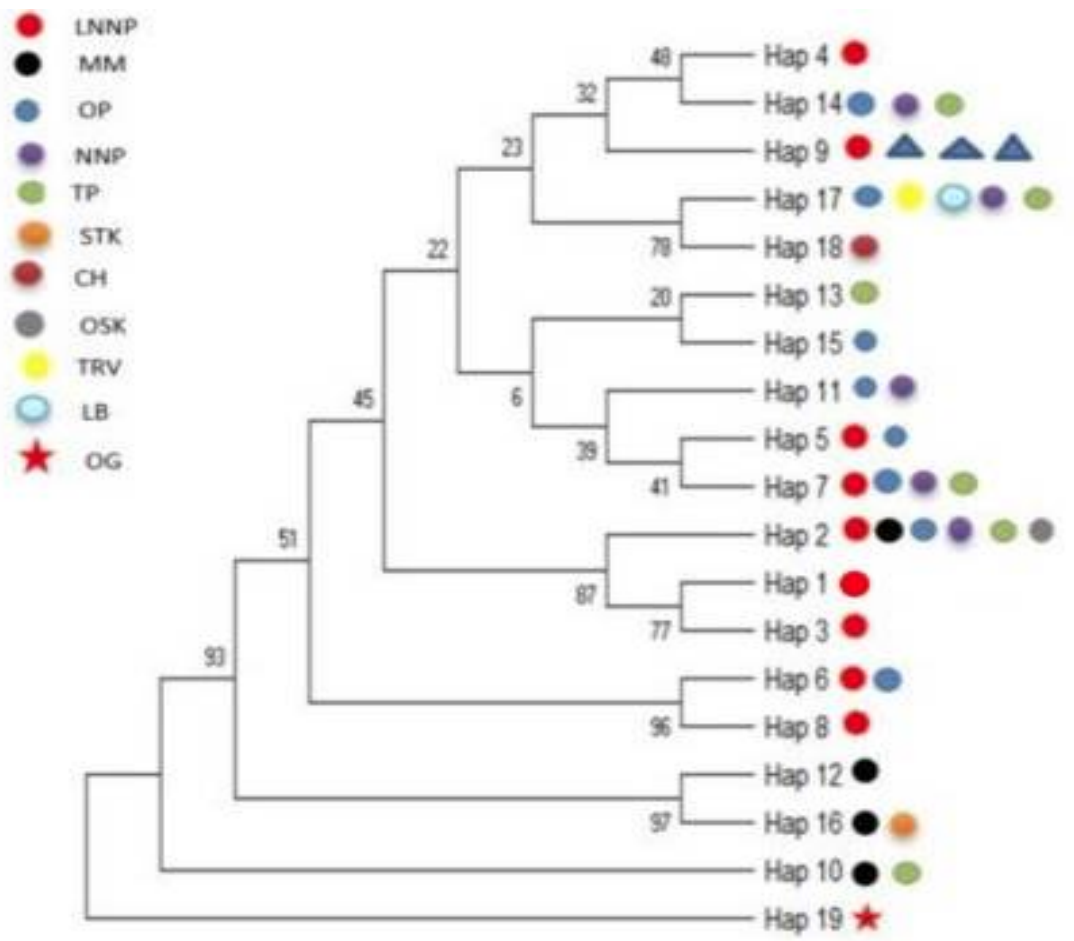

Figure 1. Maximum likelihood tree of the 18 haplotypes found in the whole rhino dataset.

A maximum likelihood tree was drawn based on 1000 bootstrap replicates (Figure 1). The Bornean rhinoceros Dicerorhinus sumatrensis harrisoni (Hap 19) was used as an out-group. Bootstrap values show percentages. The population with each haplotype is represented by colored circles; the outgroup haplotype is represented by a red star. The tree was generated using MEGA version X.

Figure 2 shows the principal coordinate analysis (PCoA) plot of PC1 and PC2 axes, which explain 55.47 and $17.58 \%$ of the variability, respectively. Only two axes were necessary to explain more than $70 \%$ of the total variation. PCoA grouped the individuals into five clusters. Cluster 1 consisted of 38 individuals from 10 subpopulations: Nairobi, Maasai Mara, Sotik, Cherangani Hills, Lake Baringo, Tsavo, Ol Pajeta, Tana River, LNNP and Isiolo. Cluster 2 included three individuals, all from the LNNP subpopulation. Cluster 3 included 10 individuals from four subpopulations: LNNP, Ol Pajeta, Maasai Mara and Sotik. Cluster 4 consisted of 23 individuals from five subpopulations: Maasai Mara, Tsavo, LNNP, Oldonyo Sabuk and Nairobi. Cluster 5 included three individuals from two subpopulations: Maasai Mara and Tsavo. The PCoA did not show any significant differentiation among subpopulations that had different haplotypes, but it revealed that each cluster consisted of a mixture of individuals that represented different haplotypes and subpopulations. 


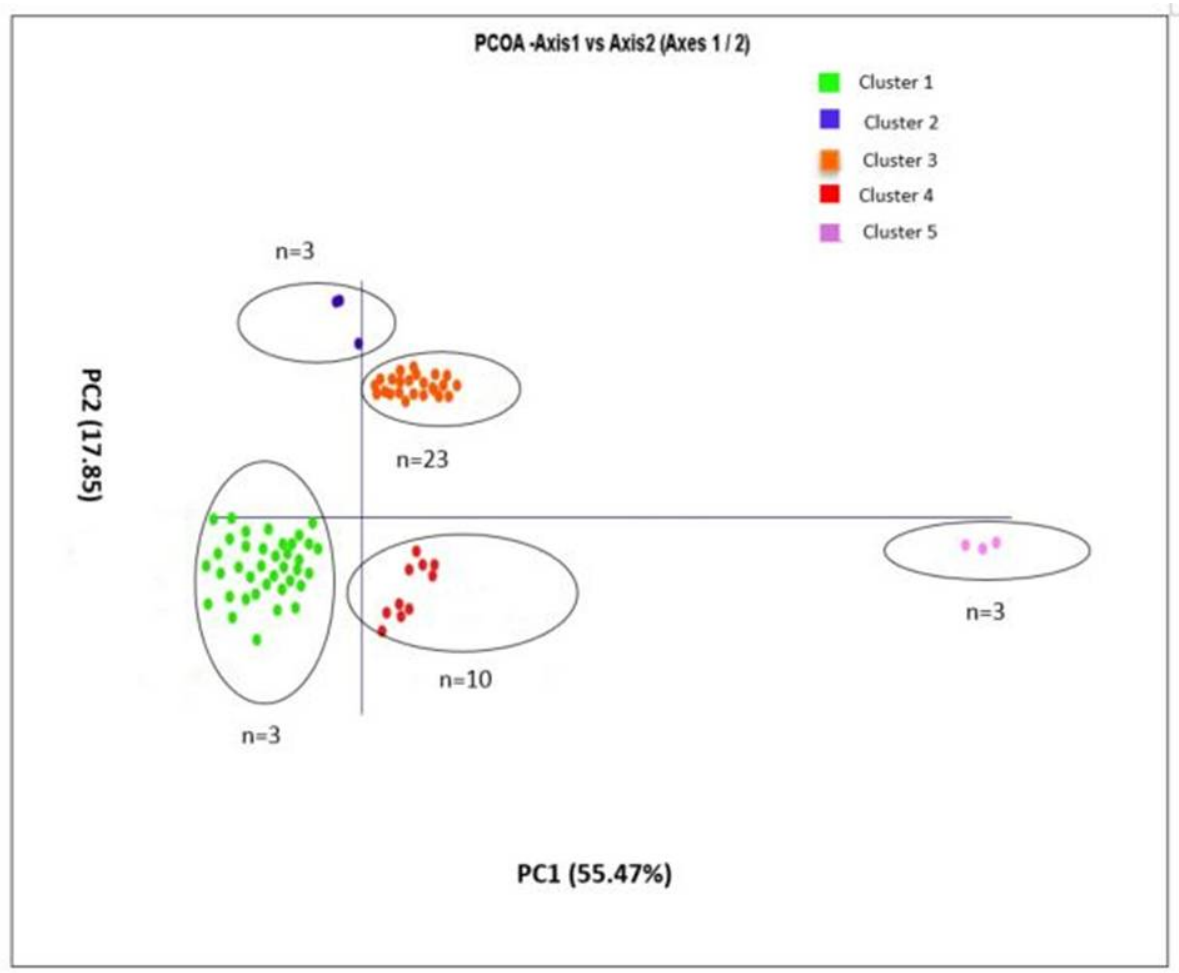

Figure 2. Plot of PC1 and PC2 of the Principal Coordinate Analysis of the rhino samples based upon the dissimilarity matrix according to Kimura (1980). The PCoA is based on $469 \mathrm{bp}$ of 77 individuals. The different colors represent different clusters. The plot was generated using the DARwin 6.0 software.

\section{DISCUSSION}

Our study clearly indicates an overall high degree of relationship between and within subpopulations (Figure 1). This demonstrates that there is a need for careful selection of candidates for translocation and reintroduction.

\section{Genetic diversity}

The high level of genetic diversity that we found in both the LNNP and KP (Table 1) was consistent with previous studies by Muya et al. (2011) and Moodley et al. (2017). Although we found greater number of haplotypes than Muya et al. (2011), the number of haplotypes in our study is similar to that of Moodley et al. (2017). In our opinion, the huge difference in the number of haplotypes between our study and Muya et al. (2011) is because the number of haplotypes they reported was a simple mean calculated by dividing the total number of haplotypes of subject subpopulations by the number of subpopulations tested. By doing so, they assumed all haplotypes are equally distributed, precluding the possibility of private and shared haplotypes. To support this analogy, we calculated the number of haplotypes of LNNP, KP and LNNP + KP separately and results from LNNP + KP was less 
than the sum of number of haplotypes calculated from LNNP and KP separately due to some shared haplotypes among the subpopulations. However, the difference may also be due to sample size or because the individuals Muya et al. (2011) analyzed came from closely related maternal lines.

Our results showed that LNNP contained half (nine haplotypes) of the total number of haplotypes found in the $\mathrm{KP}(\mathrm{Hd}=18)$, showing a moderately ample maternal genetic diversity. This may reflect a probable large historic effective population size of black rhino in Kenya or a fortunate stroke of serendipity when sourcing the LNNP founder individuals. This finding supports the population history of LNNP, as its founder individuals were animals rescued from various parts of Kenya (Muya et al., 2011).

\section{Relationships and genetic structure}

Our finding showed moderate bootstrap values of the maximum likelihood tree (Figure 1); this may be because of the overall high degree of relationship among Kenyan black rhinos (Moodley et al., 2017). The low to moderate bootstrap values are consistent with those reported in a previous mitochondrial DNA D-Loop study of black rhinos (Githui et al., 2017). Although some bootstrap values were low, the populations consistently clustered into the same grouping in the tree. The maximum likelihood tree (Figure 1) shows that individuals from LNNP share identical haplotypes with different subpopulations. This may indicate a common ancestry or possiblly an undetectable gene flow among these subpopulations.

Some maternal lines were found in both LNNP and MM. MM was previously classified as a genetically distinct subpopulation with overall reduction in genetic diversity (Muya et al., 2011); this confirms that the founder individuals came from diverse regions in Kenya. Our results further showed that MM and TP share identical maternal lines. This is logical as Maasai Mara National Reserve and Tsavo National Park have no physical barriers, thereby increasing the chances of rhino movement and consequent geneflow. The uniqueness observed in MM by Muya et al. (2011) may be because of limited sampling and may not necessarily mean the subpopulation is distinct.

The haplotype distribution analysis (Table 3) revealed that LNNP founder individuals were from six possible subpopulations: MM, TP, OSK, OP and NNP. The genetic clustering analysis PCoA explained more than $70 \%$ of the total variation, which is higher than the recommended 60\% threshold (Anderson and Willis, 2003). The PCoA plot of $469 \mathrm{bp}$ from 77 individuals grouped them in five clusters (Figure 2). However, individuals from different subpopulations were found in the same clusters; this further confirms the close relatedness and even distribution of haplotypes within the Kenyan black rhinoceros' population. Cluster 1 was the most variable, harboring $49 \%$ of the tested individuals; these suggests a historical connectivity of individuals.

\section{CONCLUSIONS}

We found that the LNNP black rhinoceros breeding population harbors high haplotype and nucleotide diversity, akin to that of the entire Kenyan population. The result also provides clear evidence that four haplotypes represented in the Kenyan population are missing in the LNNP breeding subpopulation. Further, the result demonstrated a prehistoric 
connectivity between gene pools in Kenya, contrary to what had been previously reported. This is particularly important as it should encourage conservation management authorities to consider Kenya as a single population and stop managing the Maasai Mara subpopulation separately. Finally, we contend that for LNNP to be a sustainable nucleus breeding population, all haplotypes not represented therein should be introduced through a supplementation program. We also propose a more comprehensive comparative study using nuclear markers to assess levels of relatedness between nucleus subpopulations, as a basis for identifying potential candidates for translocations.

\section{ACKNOWLEDGMENTS}

This research project was supported by a sub-grant from Professor Thomas Gilbert, University of Copenhagen, Denmark to Dr Elijah Kem Githui of National Museums of Kenya. We would also like to thank the Kenya Wildlife Service for providing the biological samples used in this study. We are grateful to an anonymous reviewer for providing useful comments and suggestions.

\section{CONFLICTS OF INTEREST}

The authors declare no conflict of interest.

\section{REFERENCES}

Amin R, Thomas K, Emslie RH, Foose TJ, et al. (2006). An Overview of the Conservation Status of and Threats to Rhinoceros Species in the Wild. Int. Zoo Yb. 40: 96-117. doi:10.1111/j.1748-1090.2006.00096.x.

Anderson MJ and Willis TJ (2003). Canonical Analysis of Principal Coordinates: A Useful Method of Constrained Ordination for Ecology Published by: Ecological Society of America. Ecology. 84: 511-25. doi:10.1890/00129658(2003)084.

Ashley M V, Melnick DJ and Western D (1990). Conservation Genetics of the Black Rhinoceros (Diceros Bicornis)." Conserv. Biol. 4: 71-180.

Biggs D, Courchamp F, Martin R and Possingham HP (2013). Legal Trade of Africa's Rhino Horns. Science. 339: 1038-39. doi:10.1126/science.1229998.

Brett RA (1990). The Black Rhino Sanctuaries of Kenya. Pachyderm. 13: 31-34.

Emslie R (2012). Diceros bicornis, Black Rhinoceros." The IUCN Red List of Threatened Species. 2012: 8235. doi:10.2305/IUCN.UK.2012.RLTS.T6557A16980917.en.

Frankham R (2005). Genetics and Extinction. Biol. Conserv. 126: 131-40. doi:10.1016/j.biocon.2005.05.002.

Frankham R, Ballou JD and Briscoe DA (2002). Introduction to Conservation Genetics. Forest Ecology and Management. Cambridge University Press. doi:10.1016/j.foreco.2003.12.001.

Fu YX (1997). Statistical Tests of Neutrality of Mutations against Population Growth, Hitchhiking and Background Selection. Genetics. 147: 915-25. doi:genetics.org//147/2/915.

Githui EK, Thuo DN, Amimo JO, Njagi NM, et al. (2017). Mitochondrial DNA Phylogenetics of Black Rhinoceros in Kenya in Relation to Southern Africa Population 2017: 8326361. doi:10.1155/2017/8326361.

Green MR and Sambrook J (2012). Molecular Cloning A Laboratory Manual. Cold Spring Harbor Laboratory Press, Vol 1. doi:10.1016/B978-0-12-418687-3.00007-0.

Hall TA (1999). BioEdit: A User-Friendly Biological Sequence Alignment Editor and Analysis Program for Windows 95/98/NT. Nucl. Acids. Symp. Ser. 41: 95-98."

Hedrick PW and Garcia-Dorado A (2016). Understanding Inbreeding Depression, Purging, and Genetic Rescue. Trends Ecol. Evol. 31940: 52. doi:10.1016/j.tree.2016.09.005.

Hilborn, Arcese P, Borner M, Hando J, et al. (2006). Effective Enforcement in a Conservation Area. Science. 314 (5803): 1266. doi:10.1126/science.1132780.

Kawabe K,Worawut R, Taura S, Shimogiri T, et al. (2014). Genetic Diversity of MtDNA D-Loop Polymorphisms in Laotian Native Fowl Populations. Asian-Australas J. Anim. Sci. 27: 19-23. doi:10.5713/ajas.2013.13443.

Kenya Wildlife Sservice (2012). Conservation and Management Strategy for the Black Rhino in Kenya, 2012-2016, 5th Edition. 1-8. 
Kimura M (1980). A Simple Method for Estimating Evolutionary Rates of Base Substitutions Through Comparative Studies of Nucleotide Sequences. J. Mol. Evol. 16: 111-20.

Kumar S, Stecher G, Li M, Knyaz C, et al. (2018). MEGA X: Molecular Evolutionary Genetics Analysis across Computing Platforms. Mol. Biol. Evol. 35: 1547-49. doi:10.1093/molbev/msy096.

Librado P and Rozas J (2009). DnaSP v5: A Software for Comprehensive Analysis of DNA Polymorphism Data $\begin{array}{llll}10.1093 / B i o i n f o r m a t i c s / B t p 187 & \text { Bioinformatics. } & \text { 25: }\end{array}$ http://bioinformatics.oxfordjournals.org/content/25/11/1451.abstract.

Markert JA, Champlin DM, Gutjahr-Gobell R, Grear JS, et al. (2010). Population Genetic Diversity and Fitness in Multiple Environments. BMC Evolu. Biol. 10: 205. doi:10.1186/1471-2148-10-205.

Moodley Y, Russo IRM, Dalton DL, Kotzé A, et al. (2017). Extinctions, Genetic Erosion and Conservation Options for the Black Rhinoceros (Diceros bicornis). Sci. Rep. 7: 41417. doi:10.1038/srep41417.

Muya SM, Bruford MW, Muigai WT, Osiemo ZB, et al. (2011). Substantial Molecular Variation and Low Genetic Structure in Kenya's Black Rhinoceros: Implications for Conservation. Conserv. Genet. 12: 1575-88. doi:10.1007/s10592-011-0256-3.

Rosetti N and Remis MI (2012). Spatial Genetic Structure and Mitochondrial DNA Phylogeography of Argentinean Populations of the Grasshopper Dichroplus elongatus. PLoS one. 7: e40807. doi:10.1371/journal.pone.0040807. PLoS ONE 7(7): e40807

Thuo DN (2015). Moderate Genetic Variation and Population Fragility in Black Rhino (Diceros bicornis michaelli) of Lake Nakuru National Park: Masters Thesis.” University of Nairobi. doi:10.13140/RG.2.1.3919.2085.

Thuo DN, Junga JO, Kamau JM, Amimo JO, et al. (2015). Population Viability Analysis of Black Rhinoceros (Diceros bicornis michaeli) in Lake Nakuru National Park, Kenya. Int. J. Biodivers. Conserv. 3 (1): 1-5. doi:10.4172/23322543.1000150 .

Vandermeer JH and Goldberg DE (2004). Population Ecology: First Principles. Princeton University Press. 1-263. doi:10.1111/j.1442-9993.2004.01359.x.

Willoughby JR, Sundaram M, Wijayawardena BK, Kimble SJA Ji Y, et al. (2015). The Reduction of Genetic Diversity in Threatened Vertebrates and New Recommendations Regarding IUCN Conservation Rankings. Biol. Conserv. 191: 495-503. doi:10.1016/j.biocon.2015.07.025.

Yacoub HA and Fathi MM (2013). Phylogenetic Analysis Using D-Loop Marker of MtDNA of Saudi Native Chicken Strains. Mitochondrial DNA. 24: 538-51. doi:10.3109/19401736.2013.770494.

Zhang JJ, Duan JR, Zhou YF, Peng JY, et al. (2017). "Genetic Diversity of Mitochondrial Control Region (D-Loop) Polymorphisms in Coilia ectenes taihuensis Inhabiting Taihu Lake, China. Genet. Mol. Res. 16: gmr16019457. doi: $10.4238 / \mathrm{gmr} 16019457$. 